\title{
Male meiosis and pollen morphology in diploid Indonesian wild bananas and cultivars
}

\author{
Fajarudin Ahmad ${ }^{1,2} \cdot$ Yuyu S. Poerba ${ }^{1} \cdot$ Gert H. J. Kema ${ }^{3} \cdot$ Hans de Jong $^{4} \odot$
}

Received: 26 November 2020 / Accepted: 12 March 2021 / Published online: 19 April 2021

(c) The Author(s) 2021

\begin{abstract}
Breeding of banana is hampered by its genetic complexity, structural chromosome rearrangements and different ploidy levels. Various scientific disciplines, including cytogenetics, linkage mapping, and bioinformatics, are helpful tools in characterising cultivars and wild relatives used in crossing programs. Chromosome analysis still plays a pivotal role in studying hybrid sterility and structural and numerical variants. In this study, we describe the optimisation of the chromosome spreading protocol of pollen mother cells focusing on the effects of standard fixation methods, duration of the pectolytic enzyme treatment and advantages of fluorescence microscopy of DAPI stained cell spreads. We demonstrate the benefits of this protocol on meiotic features of five wild diploid Musa acuminata bananas and a diploid (AA) cultivar banana "Rejang", with particular attention on pairing configurations and chromosome transmission that may be indicative for translocations and inversions. Pollen slides demonstrate regular-shaped spores except "Rejang", which shows fertile pollen grains of different size and sterile pollen grains, suggesting partial sterility and unreduced gamete formation that likely resulted from restitutional meiotic divisions.
\end{abstract}

Keywords Cytogenetics $\cdot$ Translocation $\cdot$ Musa acuminata ssp. malaccensis $\cdot$ Protocol $\cdot$ Pollen mother cells $\cdot$ Pollen

\section{Introduction}

The genus Musa L. consists of about 70 species [17], of which Musa acuminata Colla (A genome) and M. balbisiana Colla (B genome) are the leading representatives of cultivated bananas [42]. Most of the banana's wild relatives are diploid with $2 n=2 x=22$ chromosomes [42], whereas

Corresponding Editor: Umesh C Lavania; Reviewers : Jaroslav Doležel, Maki Yamamoto, Anath Bandhu Das.

Hans de Jong

hans.dejong@wur.nl

1 Research Center for Biology, Indonesian Institute of Sciences (LIPI), Jl. Raya Jakarta-Bogor Km. 46, Bogor 16911, Indonesia

2 Wageningen Plant Research, Wageningen University and Research, P.O. Box 16, 6700 AA Wageningen, The Netherlands

3 Laboratory of Phytopathology, Wageningen University and Research, P.O. Box 16, 6700 AA Wageningen, The Netherlands

4 Laboratory of Genetics, Wageningen University and Research, P.O. Box 16, 6700 AA Wageningen, The Netherlands cultivated forms can also be triploid or tetraploid as resulted from intra- or interspecific hybrids. Wild bananas are seeded with little pulp and so not appropriate for consumption, whereas most cultivated forms are seedless, parthenocarpic or sterile [18].

Banana is one of the essential fruits globally and is cultivated in tropical and subtropical countries. It is an important staple food with an annual production above 100 million tons and plays a vital role in its growers' social and cultural aspects [15]. However, banana is vulnerable to bacterial, viral and fungal pathogens, urging geneticists and breeders to search for disease-resistant varieties [6,35]. Despite various breeding initiatives [4, 22] and genetic modification [9], introgression of desired traits into cultivated forms is still very demanding, if not impossible [31].

Factors that hamper practical banana breeding include genetic complexity, structural chromosome rearrangements and unequal ploidy levels of appropriate crossing parents [41, 42], often leading to hybrid sterility, partial pollen fertility, linkage drag and crossing incompatibility $[16,29,39]$. Various studies revealed the relevance between fertility with abnormal chromosome morphology and balanced meiotic segregation in wild M. acuminata, $M$. balbisiana and their hybrids [14, 41, 44]. Most 
cultivated triploid bananas exhibit abnormal gamete production due to unbalanced chromosome segregation at meiosis, which contrasts to most wild bananas, which are in general fertile $[14,41]$. To this end, cytogenetic analyses of chromosome pairing and transmission at male meiosis of the parental and hybrid genotypes are required to establish the course of chromosome behaviour during microsporogenesis [14, 41].

Despite several long-standing cytogenetics studies of banana [14, 41, 44-46], the skill of producing high-quality microscopic preparations is still troublesome and timeconsuming. Although various authors $[1,10,20]$ claim significant improvements in making high-quality chromosome preparation, the presence of dense cytoplasm in pollen mother cells at meiotic stages is still a major challenge in getting high-quality chromosome spreads.

In this study, we aim to further optimise chromosome preparation techniques of pollen mother cells at different meiotic stages to analyse selected Indonesian bananas. We focus on the wild $M$. acuminata ssp. malaccensis, a wild banana that confers resistance to one of the most devastating banana diseases, Fusarium wilt of banana (FWB). The disease is caused by a plethora of different Fusarium species [27], of which $F$. odoratissimum, comprising the so-called Tropical Race 4 (TR4), is currently threatening "Cavendish" bananas as well as many other varieties destined for domestic markets [27, 30]. Hence, this species is considered a favourite for FWB resistance studies or for obtaining genetic improvement [8, 9, 21, 34]. Beside this accession, we also included some wild M. acuminata and cultivated bananas for comparison. We considered common fixations as part of slide optimisation to reduce cytoplasmic background and improved incubation time with pectolytic enzyme solution for better cell spreading. We analysed chromosome pairing abnormality, chromosome segregation, unreduced gamete and pollen viability. Eventually, we discussed the potential usage of this method for more intensive banana cytogenetics and insight into how cytogenetics can drive banana breeding programs in the future.

\section{Materials and methods}

The plant samples were obtained from the Research Center for Biology's living collection, Indonesian Institute of Sciences (LIPI), including M. acuminata ssp. malaccensis (LIPI-010), var. breviformis (LIPI-218), var. sumatrana (LIPI-457), var. tomentosa (LIPI-172), and var. zebrina (LIPI-043). Besides, we used the Musa AA "Rejang" (LIPI048, (Sucrier subgroup) and Musa ABB "Pisang Kepok" (LIPI-125, Saba subgroup) cultivated bananas, and one $M$. balbisiana (BB) accession "Pisang Klutuk" (LIPI-054). Detailed information on the material is given in Table 1.

\section{Chromosome preparations.}

We collected the male buds during September 2014, and March and December 2015, and always between 10 am and $3 \mathrm{pm}$. We used anthers of $20 \mathrm{~mm}$ or less in the younger parts of the male bud with pollen mother cells and microsporocytes at different meiotic stages. The material was directly fixed in one of the following solutions: a) freshly prepared ethanol (96\%): glacial acetic acid (3:1), b) methanol (100\%): acetic acid (3:1) and c) Carnoy's solution (9 ethanol: 3 chloroform: 1 acetic acid). The volume of each fixative was about $20 \times$ the volume of the materials. Fixation

Table 1 Details of accessions used in this study

\begin{tabular}{|c|c|c|c|c|}
\hline Banana & Accessions & Genome & Collection site & Details \\
\hline Musa acuminata ssp. malaccensis & LIPI-010 & AA wild & Sumatra & $\begin{array}{l}\text { A wild Musa acuminata, which is resistant to Fusarium wilt Tropical } \\
\text { Race } 4 \text { (TR4) and Race } 1 \text { [3], comparable to the fully sequenced } \\
\text { resistant ssp. malaccensis DH "Pahang" }[8,25]\end{array}$ \\
\hline M. acuminata var. breviformis & LIPI-218 & AA wild & Java & A wild $M$. acuminata in lowland with green pseudostem and leaf \\
\hline M. acuminata var. sumatrana & LIPI-457 & AA wild & Sumatra & $\begin{array}{l}\text { A wild } M \text {. acuminata in mountainous rain forests with hanging verti- } \\
\text { cal bunch }\end{array}$ \\
\hline M. acuminata var. tomentosa & LIPI-172 & AA wild & Sulawesi & A wild $M$. acuminata with light green leaves and pseudostem \\
\hline M. acuminata var. zebrina & LIPI-043 & AA wild & Java & $\begin{array}{l}\text { A wild } M . \text { acuminata with reddish coloured pseudostem in young } \\
\text { leaves and the lower surface of the leaves }\end{array}$ \\
\hline "Rejang" & LIPI-048 & AA cv & Sumatra & $\begin{array}{l}\text { Fusarium TR4 resistant banana with slim fruits of about } 10 \mathrm{~cm} \text { and } \\
\text { sweet taste }\end{array}$ \\
\hline "Pisang Kepok" & LIPI-125 & $\mathrm{ABB} \mathrm{cv}$ & Java & $\begin{array}{l}\text { A popular cooking banana in Indonesia with high starch content and } \\
\text { resembles members of Saba sub-group }\end{array}$ \\
\hline M. balbisiana "Pisang Klutuk" & LIPI-054 & BB wild & Java & A wild $M$. balbisiana, commonly grown in the villages for wrapping \\
\hline
\end{tabular}



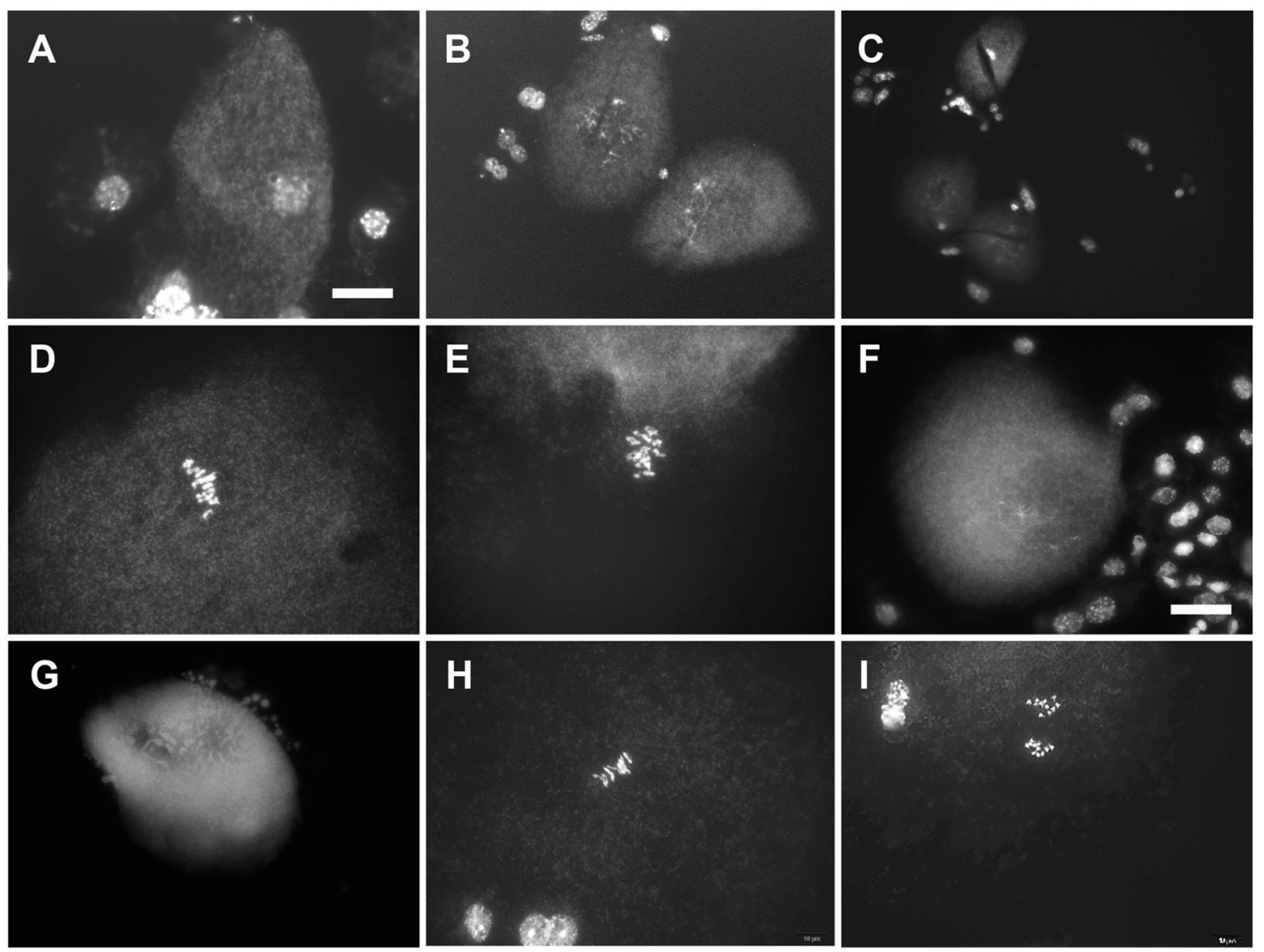

Fig. 1 Optimisation of the chromosome spreading protocol. A-C: Effect of incubation time of the pectolytic enzyme solution on morphology of the pollen mother cells (PMCs) of Musa acuminata ssp. malaccensis. A Intact PMCs after $2 \mathrm{~h}$ of incubation; B After $3 \mathrm{~h}$ of enzymes treatment, cells still have relatively good and round shape, C Incubation time of 4-5 h. D-I. Effect of fixations. The cells in D and $\mathbf{E}$, which were fixed in ethanol-acetic acid (3:1) solution, display relatively strong background of the cytoplasm, and hence ham-

time was approximately one hour at room temperature. We replaced the fixative 1-2 times until the inflorescences and solution remain clear. Finally, we transferred the material to $70 \%$ ethanol for more extended storage at $4{ }^{\circ} \mathrm{C}$. On the day of slide preparation, we selected the anthers and washed them three times in Milli-Q water (MQ-water) for one minute. Five to ten anthers were put in a $1.5 \mathrm{~mL}$ plastic tube, filled with $200 \mu \mathrm{L}$ pectolytic enzyme solution $(0.2 \%$ pectolyase Y23 (Sigma P-3026), 0.2\% cellulase RS (Yakult 203,033, Yakult Pharmaceutical, Tokyo, Japan) and $0.2 \%$ cytohelicase (Bio Sepra 24,970-014)), in $10 \mathrm{mM}$ sodium citrate buffer (pH 4.5), and kept for $1-5 \mathrm{~h}$ at $37^{\circ} \mathrm{C}$, depending on the condition of the material and the enzymatic activity. Subsequently, we washed the anthers three times with MQ-water per clear structures in nuclei and chromosomes. The cells in $\mathbf{F}$ and G came from anthers that have been fixed in Carnoy's solution (ethanol—chloroform-acetic acid (9:3:1)), which result in even denser cytoplasmic background and also less distinct chromosomes. In $\mathbf{H}$ and $\mathbf{I}$ we use a methanol-acetic acid (3:1) fixative instead, that produce a more transparent background. Scale bars in A, B, F and G equal $20 \mu \mathrm{m}$. Scale bar for C equals $30 \mu \mathrm{m}$. Scale bars in D, E, H and I equal $10 \mu \mathrm{m}$

and kept them on ice until use. For the chromosome spreading step, we transferred a 1-2 $\mathrm{mm}$ part of an anther onto a clean glass slide along with a tiny amount (c. $5 \mu \mathrm{L}$ ) of water. The anther was then tapped with a glass rod or needle, after which the pollen mother cells (PMCs) were squeezed out and the larger clumps of supporting tissues removed. We then added 2-3 drops of 50\% acetic acid, covered with a coverslip and incubated the cells for $5-10 \mathrm{~min}$ at $45^{\circ} \mathrm{C}$, while adding small amounts of acetic acid to avoid drying out of the preparation. We then squashed the material with a needle and thumb. We removed the coverslip after freezing the slide in liquid nitrogen and let it air-dry. Alternatively, we squeezed the PMCs in acetic acid 50\%, then added 2-3 drops of freshly prepared ethanol-acetic acid (3:1) and flame 
dried the slide. Slides were stained with $100 \mu \mathrm{g} / \mathrm{mL}$ DAPI (4',6-diamidino-2-phenylindole) in Vectashield ${ }^{\circledR}$ (Vector Laboratories) mounting solution (1:20) for analysis under a Zeiss fluorescence microscope equipped with appropriate filters and epifluorescence illumination. During the slide screening, we found that pollen mother cells at pachytene were most common.

In contrast, we counted 142 cells at the diakinesis/metaphase I stage, 29 cells at anaphase I and five cells at anaphase II. Digital images were eventually optimised for contrast, brightness and sharpness in Adobe Photoshop [20]. Pollen morphology and viability were established in pollen slides stained in a drop of Lactophenol acid fuchsin [40]. Images were captured of 100-150 pollen grains using a bright-field microscope. Pollen grains were measured with Fiji/ImageJ (https://imagej.net/Fiji) and data processed in Microsoft Excel.

\section{Results}

Our first goal was to optimise our protocol for minimum cytoplasm, and improved chromosome morphology in cell spread slides containing pollen mother cells (Fig. 1). Most crucial is the effect of fixation and maceration in the protocol. The best cell spreading and chromosome differentiation was obtained with the methanol-acetic acid fixative (Figs. 1H-I). The ethanol-acetic acid mixture, on the
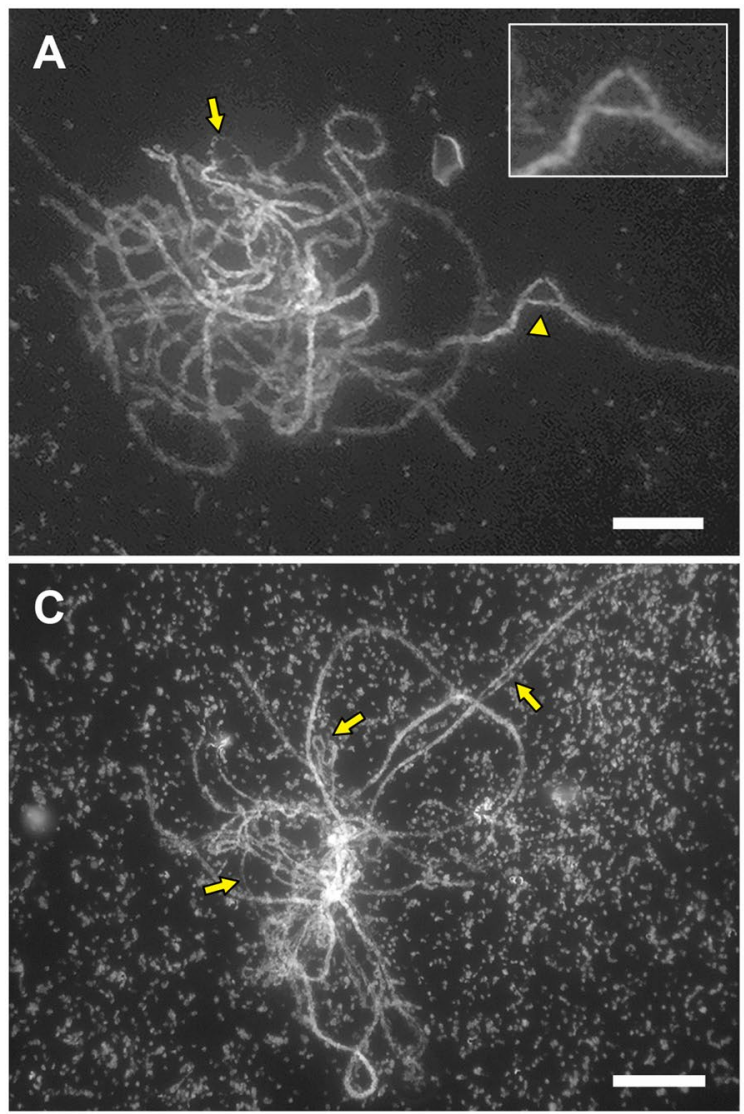

Fig. 2 Pachytene complements in pollen mother cells of wild Musa acuminata and "Rejang". A M. acuminata ssp. malaccensis. Chromosomes display numerous small chromomeres, in addition to brighter fluorescing segments that represents the pericentromere heterochromatin. The arrowhead denotes an open chromosome confirmation indicative of a paracentric inversion; the arrow shows a part of the
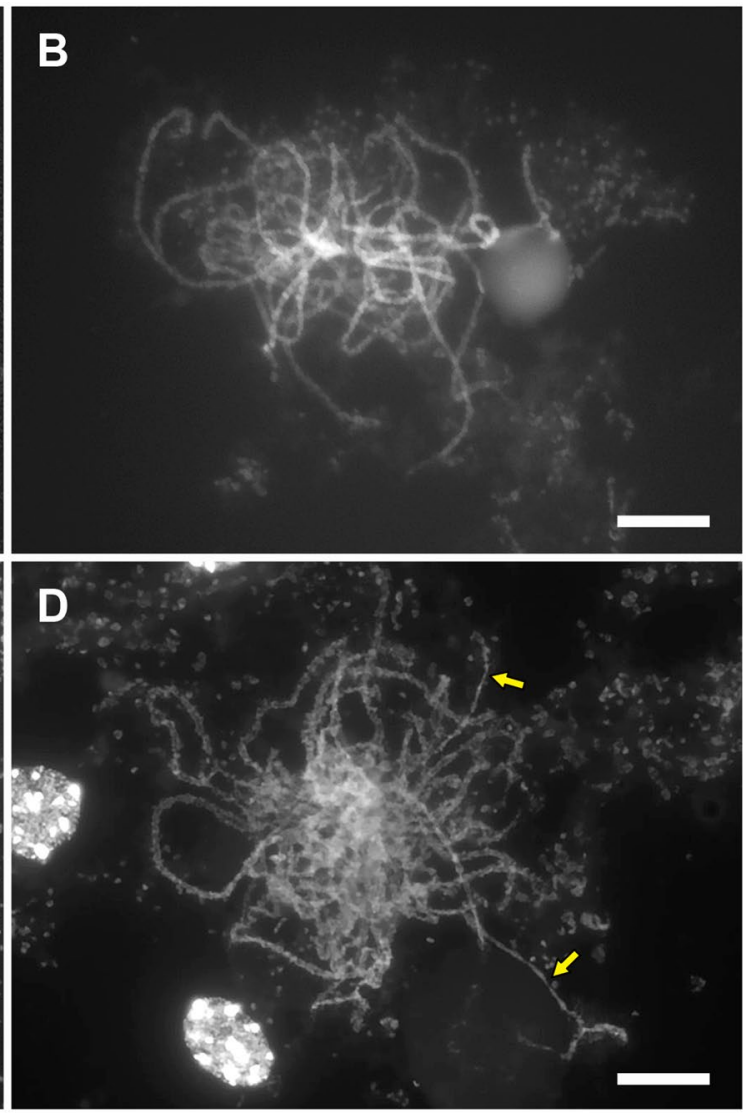

chromosomes that are unpaired. B Var. zebrina. Fully paired cell complement. C Var. breviformis. This pollen mother cell is at late zygotene / early pachytene stage with several chromosome regions not fully paired (arrows). D "Rejang". The arrows show examples of unpaired chromosome regions. Scale bars equal $10 \mu \mathrm{m}$ in the figures 
Fig. 3 Pollen mother cells at late prophase I (diplotenediakinesis) of wild Musa accuminata and "Rejang". A Diffuse diplotene of a pollen mother cell of var. tomentosa. B Late diplotene cell of ssp. malaccensis. The arrow points at a quadrivalent. C Late diplotene of ssp. malaccensis. The arrow shows two univalents. D Late diplotene of var. zebrina. The two arrows show groups of 4 chromosomes, which may represent quadrivalents. E-F Late diplotene of ssp. malaccensis. The arrows show two univalents. G-H Late diplotene of "Rejang". The cell complement here is tetraploid $(2 n=4 x=44)$. Arrows indicate univalents. Magnification in all figures is the same. Scale bar equals $10 \mu \mathrm{m}$
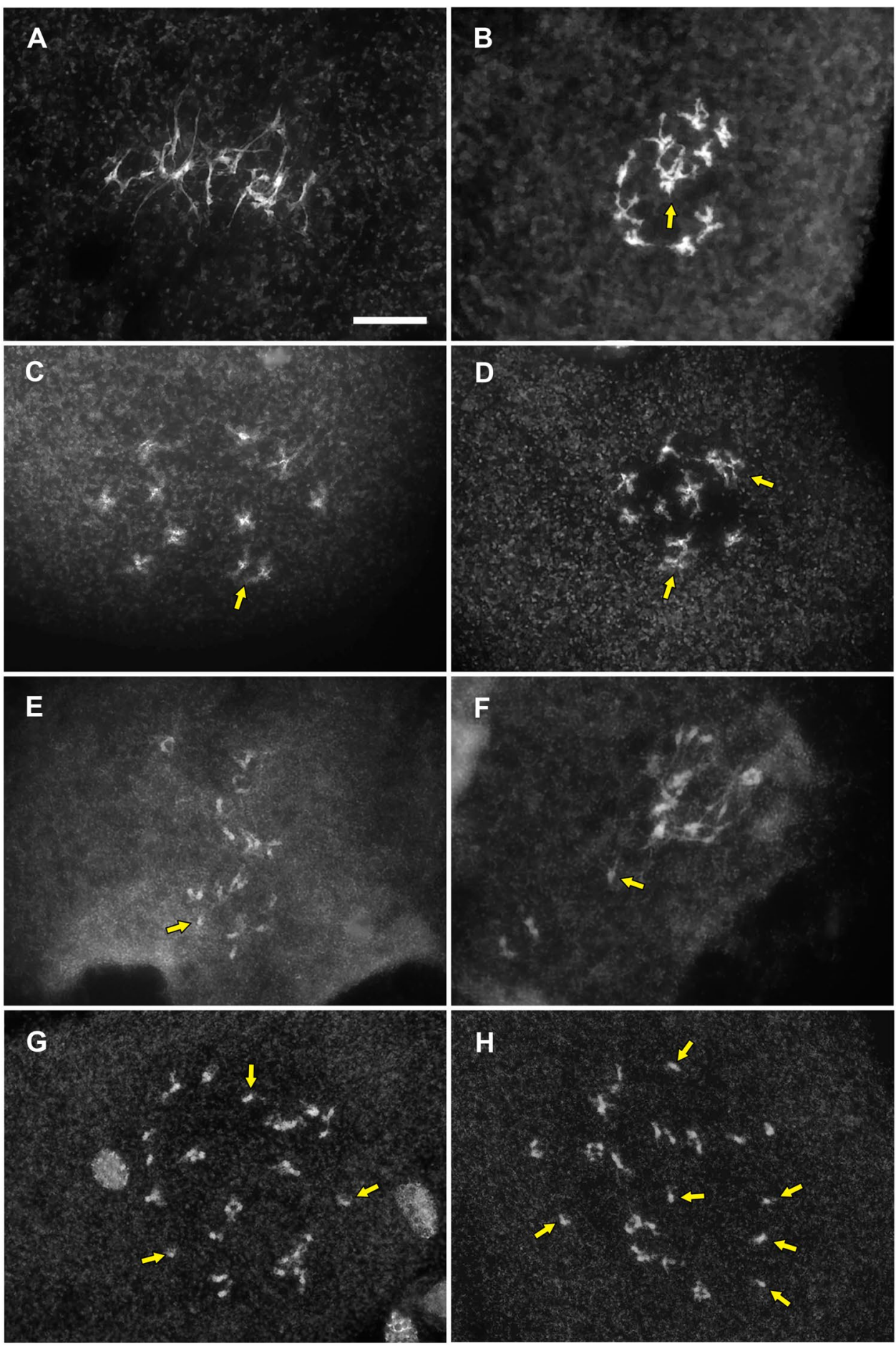

other hand, produces brighter staining of the cytoplasm and blurred chromosome boundaries (Figs. 1D-E), whereas Carnoy's (ethanol-chloroform-acetic acid) resulted in an even more opaque cytoplasm in which chromosomes are hardly discernible (Figs. 1F-G). Further optimisation was obtained with the incubation of the anthers in pectolytic 
Table 2 Mean of chromosome configurations of univalent and bivalent at diakinesis/metaphase I in wild Musa acuminata and "Rejang". Some of the chromosome configurations that could not be interpreted unequivocally were not considered and so making the total number of chromosomes less than the expected 24 chromosomes

\begin{tabular}{llll}
\hline Banana & No. of cell & \multicolumn{2}{l}{ Diakinesis I } \\
\cline { 3 - 4 } & & I & II \\
\hline ssp. malaccensis & 93 & 0.02 & 10.19 \\
var. zebrina & 7 & 0.00 & 10.43 \\
var. sumatrana & 15 & 0.00 & 10.33 \\
var. breviformis & 11 & 0.36 & 10.73 \\
"Rejang" & 16 & 0.44 & 10.81 \\
\hline
\end{tabular}

enzymes. Treatment of two hours resulted in well-spread PMCs (Fig. 1A). In contrast, three hours' treatments often resulted in damaged cells (Fig. 1B), an artefact that becomes more severe when the enzyme treatment was extended to 4-5 h (Fig. 1C).

\section{Microscopic observations of pollen mother cells and pollen}

The first meiotic prophase stage with discernible chromosomes in Musa is pachytene, in which homologous chromosome segments are fully paired. Chromosomes display a delicate pattern of numerous minor heterochromatic knobs or chromocenters in the euchromatic part and denser, brighter fluorescing segments in most heterochromatic pericentromeres. We measured the length of full pachytene complements in a few cells showing values of 207, 293, 329 and $339 \mu \mathrm{m}$, respectively. In pachytene cells of the ssp. malaccensis and var. breviformis varieties, we observed unpaired regions of the chromosomes (Figs. 2A, 2C) or longer unpaired segments (Fig. 2D), such as in "Rejang". In ssp. malaccensis, we also detected a region with unpaired chromosomes that suggest a lack of homology or a pairing partner switch.

Chromosomes at diplotene are largely decondensed, forming diffuse networks of threads (Fig. 3A). Their axes are no longer distinguishable, and hence is this stage not
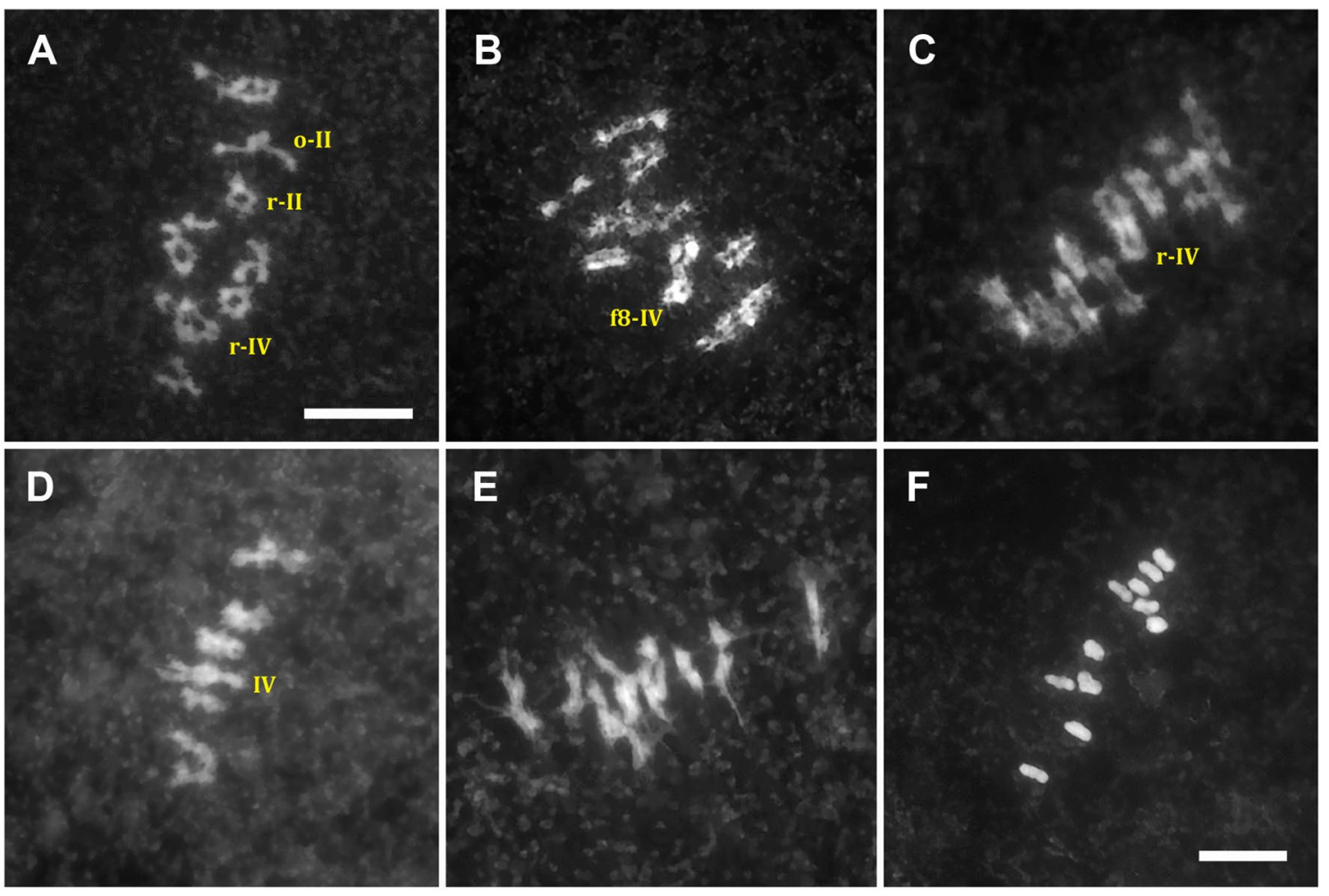

Fig. 4 Pollen mother cells at (pro)metaphase I of wild Musa accuminata. A-C: Ssp malaccensis. A Prometaphase I cell that clearly shows ring bivalents (rII), with chiasmata in both chromosome arms and rod bivalents (o-II) with (mostly) one chiasma in one of the arms. The arrow shows the r-IV that represents a ring quadrivalent with associations of the four chromosomes belonging to one translocation complex. B In this cell a rare type of a quadrivalent is visible, the arrow shows the representing a real "Fig. 8"-IV configuration, which can be formed when both interstitial translocation segments are large enough to have a chiasma simultaneously. $\mathbf{C}$ In this cell nine bivalents and one quadrivalent. The arrow shows one adjacent oriented ring-IV. D Var. sumatrana. Incomplete metaphase I cell with one quadrivalent (IV). E Var. tomentosa cell with 11 bivalents. F Var. zebrina late metaphase I cell with 11 bivalents. Scale bars equal $10 \mu \mathrm{m}$. Magnification in the figures $\mathbf{A}-\mathbf{E}$ is the same 
Table 3 Mean number of chromosomes with normal balanced (diploid like) segregation, bridges and laggards at anaphase I

\begin{tabular}{lllll}
\hline Banana & No. of cell & \multicolumn{2}{l}{ Anaphase I, mean of } \\
\cline { 3 - 5 } & & $\begin{array}{l}\text { Normal } \\
\text { Segregation }\end{array}$ & Bridge & Laggards \\
\hline ssp. malaccensis & 12 & 10 & 0.08 & 0 \\
var. zebrina & 5 & 11 & 0 & 0 \\
var. sumatrana & 8 & 11 & 0 & 0 \\
"Rejang" & 4 & 8.25 & 0.25 & 0.75 \\
\hline
\end{tabular}

suitable for establishing chromosome configurations. After the diffuse diplotene, chromosomes recondense and display characteristic chromosome configurations, most of which with chiasmata in both chromosome arms (ring bivalent) or in one arm (rod bivalents). Incidentally, we observed univalent pairs and configurations that resemble trivalents and quadrivalents or overlapping bivalents and/or univalents
(Figs. 3B-F). In "Rejang", we detected cell complements with several univalents (Figs. 3G-H). The average number of bivalents per cell in the ssp. malaccensis, var. zebrina, var. sumatrana and "Rejang" were 10.19, 10.43, 10.33 and 10.81 , respectively (Table 2). Few of the cell complements of ssp. malaccensis, var. breviformis and "Rejang" clearly showed one or more univalents. In "Rejang" univalent pairs occurred at 0.44 per cell. Several cases of overlapping bivalents were noted in the ssp. malaccensis, var. zebrina and "Rejang", structures that resemble alternate ring quadrivalents (Fig. 4A), "figure-8" like (Fig. 4B) and adjacent ring quadrivalents (Fig. 4C).

Chromosome segregation at anaphase I was in most cases balanced, forming two groups of 11 chromosomes in cell spreads of ssp. malaccensis, var. zebrina, var. sumatrana. In "Rejang", we found unbalanced segregations (Table 3). Bridges and lagging chromosomes were incidentally found in ssp. malaccensis and "Rejang" (Figs. 5B-C). The very short metaphase II and anaphase II stages were only found
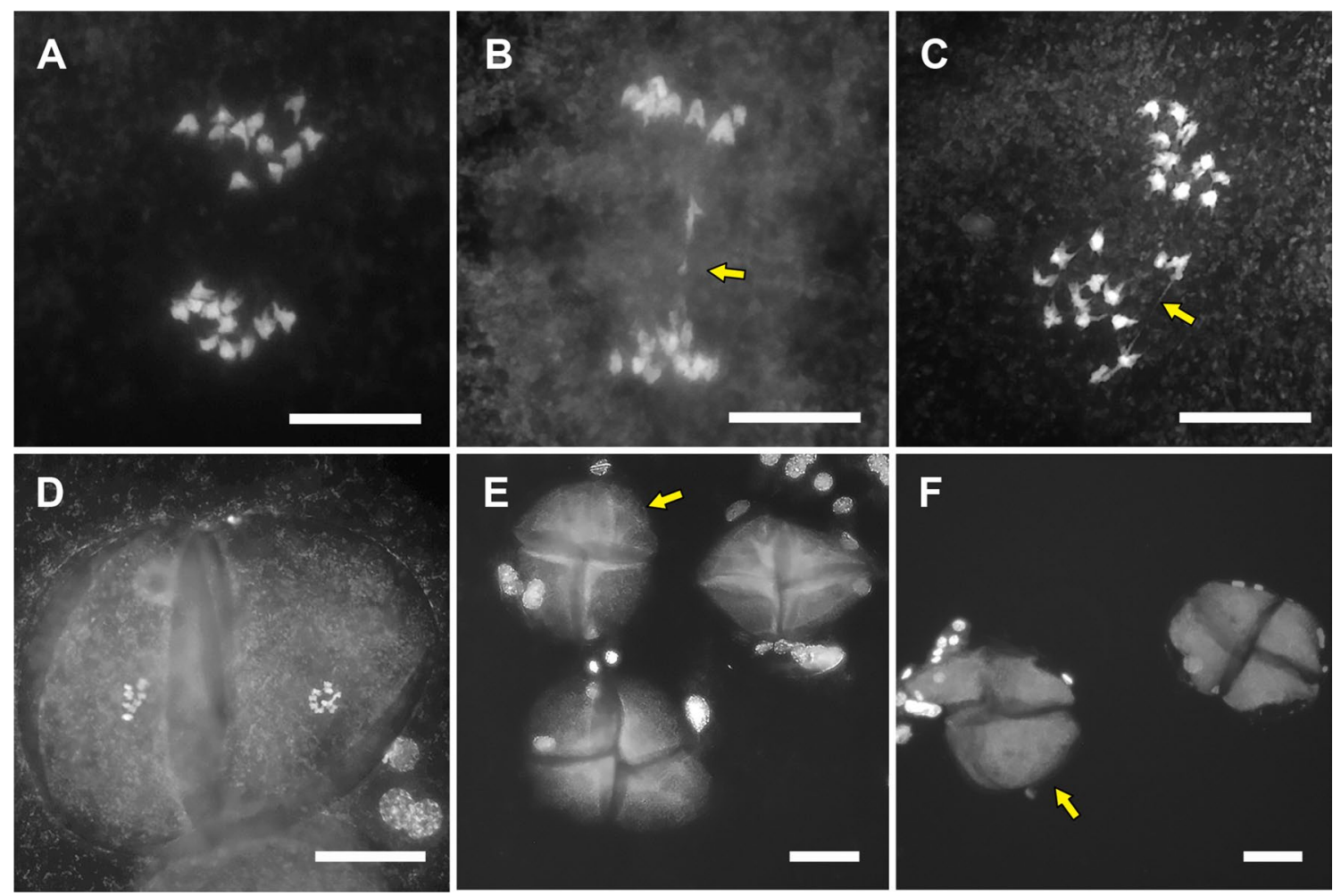

Fig. 5 Pollen mother cells at anaphase I-II of wild Musa accuminata. A Ssp. malaccensis. Balanced segregation of $11+11$ chromosomes at anaphase I. B Ssp. malaccensis. Anaphase I bridge (arrow), which most likely resulted from a crossover in a paracentric inversion loop. The expected acentric fragment produced during the same recombination event is not visible here. C "Rejang". Example of an unbalanced $(10+1+11)$ chromosome segregation. The lagging chromosome in the equatorial plane (arrow) of this anaphase I cell will most likely not be included in one of the daughter cells and so get lost as a micronucleus, or is included in the bottom group of chromosomes maken the segregation $10+12$. D Ssp. malaccensis. Pollen mother dyad at interkinesis, with $11+11$ balanced chromosome segregation (not all chromosomes are in the focal plane). E Var. tomentosa. Tetrad stage. One of the pollen mother cells has no anaphase II in one part of the dyad and hence forms a larger unreduced cell complement (arrow). F Ssp. malaccensis. Also, in this example one half of the dyad did not form a callose wall and is supposed to contain an unreduced cell complement. Scale bars in A, B and C equal $10 \mu \mathrm{m}$. Scale bar in D equals $20 \mu \mathrm{m}$. Scale bars in $\mathrm{E}$ and $\mathrm{F}$ equal $30 \mu \mathrm{m}$ 

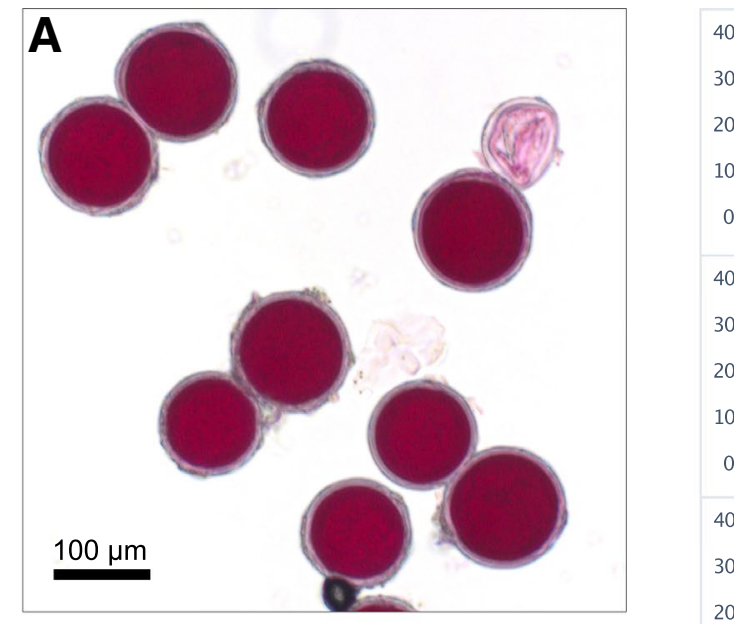

30

20

10

30

20

10

40

30

20

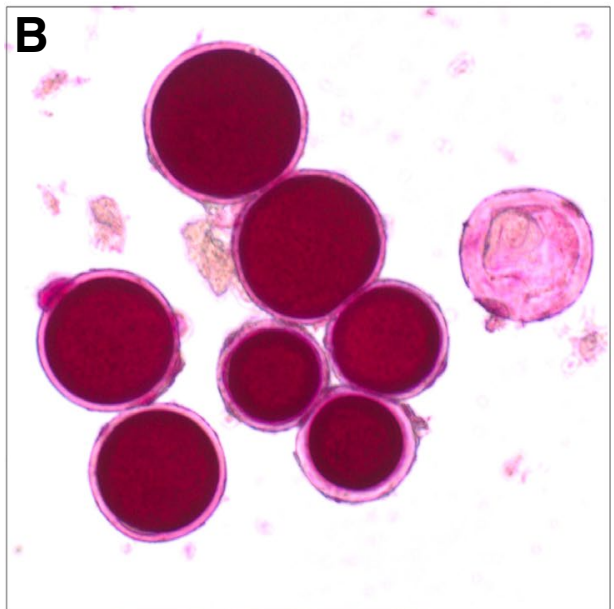

(n)

30

20

10

0

20

10

0 var. malacce

(2)

$---\square \square \square \square+-$

var. breviformis
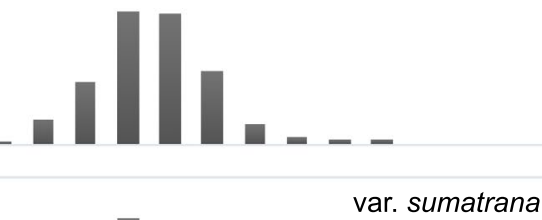

var. sumatrana

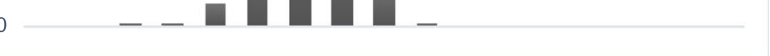

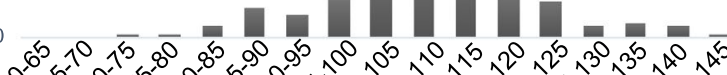

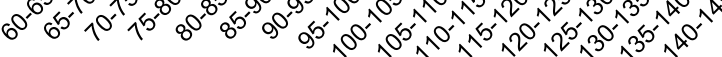

Fig. 6 Pollen morphology of lactophenol fuchsin stained pollen samples of wild Musa accuminata and "Rejang". A Ssp. malaccensis, B "Rejang". Viable pollen was stained, in contrast to the dead pollen

in anthers of ssp. malaccensis. Eight pollen mother cells at metaphase II showed balanced sets of $11+11$ chromosomes and three cells at anaphase II with four sets of four chromatids $(11+11+11+11)$. Furthermore, in a sample of 16 cells at the tetrad stage in ssp. malaccensis, we counted one triad, six dyads and nine normal tetrads.

The lactophenol acid fuchsin staining of fixed anthers was used for establishing pollen morphology and size. In most cases, pollen displayed regularly shaped grains, most likely representing viable spores, but we also observed few shrunken, irregular unstained pollen grains (Figs. 6A, B). The percentages of normal stained and regular pollen amounted to $99.5,99.8,99.6,98.7$ and $77.7 \%$ for the ssp. malaccensis, var. breviformis, var. sumatrana, and var. zebrina and "Rejang", respectively. Average pollen diameter varies from 85-95 $\mu \mathrm{m}$ in ssp. malaccensis to $100-115 \mu \mathrm{m}$ in "Rejang", in "Rejang". We see a vast range of pollen size (Fig. 6). that is often shrunken, irregular shaped and unstained (arrow). Right: Graphical representation of the percentage distribution (Y-axis) of pollen grain size (X-axis) for the five bananas

\section{Discussion}

In this study, we optimised cell spreading conditions for six Indonesian bananas to establish clear interpretations of meiotic abnormalities. The starting point was using a technique that features short fixation, enzymatic cell wall digestion and maceration of the pollen mother cells, cell spreading followed by air-drying and finally, DAPI staining for high-resolution fluorescence microscopy. The most challenging hurdle was the opaque cytoplasm of microsporocytes, in which phenolic and polysaccharide compounds mask chromosomal details from observation. We found that methanol-acetic acid $(3: 1)$ rather than the standard ethanol acetic acid (3:1) mix decreases cytoplasmic background, although some granular background always remains [10]. Previous studies claimed the superior property of methanol for fixation and low cytoplasmic background in mouse and human lymphocytes [23]. Besides, Iovene et al. [19] used methanol instead of ethanol 
for improved cell spreading and well-differentiated morphology of tomato and potato pachytene complements. Bakry \& Shepherd [5] also used a fixation of 1 part ethanol: 4 parts glacial acetic acid: 5 parts water for banana root tip material. Still, we could not test this method in our study. The second optimised step in this study was pectolytic enzymes' time to digest anther's callose walls to obtain well-spread PMCs. The optimum incubation time of two hours was in the range of that used by Kantama et al. [20] but differed slightly in the methods of Adeleke et al. [1] and De Capdeville et al. [10], most likely by the use of different genotypes and age of the fixed material that stored up to months. In our experiment, we used relatively fresh material stored in ethanol $70 \%$ for no more than two months. Despite the protocol adjustments, we still keep some cytoplasmic background and more dense in "Pisang Klutuk" (M. balbisiana, BB) and "Pisang Kepok" (ABB) (data unpublished), which requires further adaptation of cell spreading conditions.

The first meiotic stage that we analysed was late pachytene, in which the total chromosome complements measured 207-339 $\mu \mathrm{m}$, about ten times longer than their mitotic counterparts [32] and with a contraction in the range of most plant species [12]. The long pachytene chromosomes are excellent for studying the well-defined euchromatin/heterochromatin differentiation and pairing of structural chromosome rearrangements. The blue fluorescing DNA-specific DAPI is more appropriate to reveal fine details of the chromosomes [10, own study] than the protein-based staining methods [1]. Musa chromosomes show a characteristic heterochromatin pattern of numerous chromomeres, small heterochromatin knobs distributed in the distal and interstitial segments of the chromosomes, and larger and much brighter fluorescing segments in the pericentromere heterochromatin. Based on previous published genomic information [8, 25], we suggest that such chromomeres are islands of Copia retrotransposon clusters and that pericentromeres are sites enriched of Gypsy and other unclassified (satellite) repeats, regions known to be notoriously tricky in gap closure of the pseudomolecules genome assembly.

Pachytene complements are the primary sources for elucidating disturbances in pairing between homologous and homoeologous chromosomes. The late part of this stage (late pachytene) is most suitable for such analysis as chromosomes become detached from their densely clustered synizesis knot [28]. The first class of pairing abnormalities seen in our materials are the asynaptic regions in the ssp. malaccensis, var. breviformis and "Rejang" and were also mentioned in the study of pachytene spreads in a wild $M$. acuminana "Calcutta 4" by Adeleke et al. [1]. The most obvious explanation for such structural aberrations is heterozygosity for a paracentric (or less common pericentric) inversion. Other reasons include large deletions, or insertion duplications are very unlikely, as they are (sub)lethal or infrequent $[13,24]$. If the assumed inversion is large enough, a loop can be formed, and if a crossover in the loop takes place, a dicentric chromosome pair and acentric fragment will be created, as can be seen in metaphase Ianaphase I/II cells of ssp. malaccensis (Fig. 5B), although the expected acentric fragment as previously seen in the triploid M. acuminata cv. "Hom" [20] was not detectable. Wilson [44-46] showed comparable anaphase bridges in camera lucida drawings of Musa pollen mother cells, but detailed interpretations were not given. However, Dodds [14] gave more extensive descriptions of such bridges and fragments in a diploid M. acuminata clone and concluded that such meiotic disturbances resulted from crossovers in heterozygous inversion segments. Shepherd [41] described in his monograph of Musa cytogenetics a large number of cases of inversion type bridges observed in many species and hybrids, making inversions common chromosome rearrangements in this genus, in both intraspecific and interspecific hybrids. Unequivocal criteria for identifying inversions were the presence of chromatid bridges associated with a specific fragment at anaphase I, which he interpreted as the result of crossing over between relatively inverted segments. Less clear is a proper explanation of the bridges when acentric fragments were minute or even missing, assuming that inversions were very small and nearly at the chromosome's distal end. As we never observed more than a single anaphase bridge in the ssp. malaccensis and "Rejang" assume that only a single inversion exists in these heterozygotes and thus will not have a severe negative effect on gamete fertility.

Translocations represent the second group of major structural chromosome rearrangements. The most common type is the interchange of a reciprocal translocation with two translocation chromosomes and their corresponding nonhomologous chromosomes, forming a translocation complex at pachytene. Only in ssp. malaccensis, we observed an asynaptic region that may hint at a translocation breakpoint. A more accurate description of translocation complexes can be obtained by electron microscopic analysis of spread synaptonemal complex preparations [11]. Still, the low number of suitable pachytene meiocytes in an anther and the expected problems with hypotonic bursting of the dense cytoplasm made us refrain from using this technology. In the recent studies that used the sequencing database of $M$. acuminata ssp. malaccensis reverence chromosomes [26] and chromosome painting [43], a translocation event between chromosomes 1 and 4 was present in ssp. malaccensis. However, convincing proof for translocation heterozygosity in our material was expected from metaphase I complements. In the ssp. malaccensis and var. zebrina, and "Rejang", we observed overlapping bivalents that may indicate alternate (zigzag oriented) quadrivalents. However, the occurrence of adjacent quadrivalents that form conspicuous 
configurations that lead to unbalanced spores were never found; neither did we find unbalanced chromosome numbers at anaphase I / II or many sterile pollen grains. A recent genetic study of ssp. malaccensis [2] showed homozygosity for a $1^{4} / 4^{1}$ translocation, which confirmed the lack of quadrivalents at diakinesis/metaphase I cells.

An interesting observation of "Rejang" is the occurrence of many univalents that point at partial synapsis or failure of chiasma formation. Indeed, examples of incomplete pairing were seen in the pachytene complements that at least partly could account for the observed univalents. The larger number of univalents is expected to lead to unbalanced gametes, and so to a wider variation in pollen size in the lactophenol acid fuchsin stained pollen preparations. The observed univalents suggest that this banana may be segmental polyploid. These univalents indicate a lack of homology, as observed in progenies of synthetic allodiploids of Brassica rapa and Raphanus sativus [33]. Further study of "Rejang" is needed to see if homoeologous differences of the parental genomes can explain the explained lack of pairing/recombination.

Our study found several examples of mitotic and meiotic restitutions leading to doubling of the chromosome numbers. Mitotic chromosome doubling was observed only once in a slide with 44 chromosomes at diakinesis in a diploid 'AA' cultivated banana, "Rejang". Such a doubling of the chromosomes likely resulted from a premeiotic restitutional mitosis as previously reported in the triploid banana "Cavendish" and "Gros Michel" [36]. A second phenomenon is meiotic restitution in banana, which give rise to monads, dyads or triads at the tetrad stage of diploid banana, caused by first divisional restitution (FDR) or second division restitution (SDR) or a combination of both [14]. In the case of a triad, we assume the failure of anaphase II (SDR) in only one of the dyads. So, one daughter cell is unreduced while the other two smaller cells are haploid. In "Rejang" cells, chromosome doubling might be one of the explanations for the larger pollen size compared to other diploid bananas (Fig. 6). In polyploid plants, nuclear restitution is most likely due to unbalanced segregation between a group chromosome with two complement chromosomes and a group of single complement or the complete lack of anaphase I segregation (First division segregation, FDR). Moreover, meiotic restitution in diploids and polyploids can also occur by second division restitution, SDR, mostly by deficient spindle orientation at anaphase II [7, 37]. Considering these events, it is plausible to explain how triploid bananas might have resulted from hybridisation or crosses between diploid bananas [38].

Author's contributions FA and HdJ designed this study and carried out the experiments. YSP helped with the selection of banana materials for this study. FA, GK and HdJ wrote the manuscript and GK and HdJ supervised the project.
Funding This research is part of a program entitled "The Indonesian banana: Protecting a staple food from Panama disease collapse and exploiting its genetic diversity for discovery research" between the Research Centre for Biology-Indonesian Institute of Sciences and Wageningen University \& Research under Scientific Programme Indonesia-Netherlands (SPIN) join project. Banana research at WUR is supported by the Dutch Dioraphte Foundation Endowed Chair in Tropical Phytopathology at the WUR-Laboratory of Phytopathology.

\section{Declarations}

Conflict of interest The authors declare no conflict of interest in this study.

Open Access This article is licensed under a Creative Commons Attribution 4.0 International License, which permits use, sharing, adaptation, distribution and reproduction in any medium or format, as long as you give appropriate credit to the original author(s) and the source, provide a link to the Creative Commons licence, and indicate if changes were made. The images or other third party material in this article are included in the article's Creative Commons licence, unless indicated otherwise in a credit line to the material. If material is not included in the article's Creative Commons licence and your intended use is not permitted by statutory regulation or exceeds the permitted use, you will need to obtain permission directly from the copyright holder. To view a copy of this licence, visit http://creativecommons.org/licenses/by/4.0/.

\section{References}

1. Adeleke MTV, Pillay M, Okoli BE. An improved method for examining meiotic chromosomes in Musa L. HortScience. 2002;37:959-61.

2. Ahmad F, Bourke P, Schouten H, Volkaert H, de Jong H. Cytogenetics of structural rearrangement in Musa hybrids and cultivars. In: Kema G, Drenth A, editors. Achieving sustainable cultivation of bananas Volume 2: Germplasm and genetic improvement. Cambridge, UK: Burleigh Dodds Science Publishing; 2020. In press.

3. Ahmad F, Martawi NM, Poerba YS, de Jong H, Kema GHJ. Genetic mapping of Fusarium wilt resistance in a wild banana Musa acuminata ssp. malaccensis accession. Theor Appl Genet. 2020; 133:3409-18.

4. Bakry F, Carreel F, Jenny C, Horry JP. Genetic improvement of banana. Breed Plant Tree Crop Trop Species. 2009;3-50.

5. Bakry F, Shepherd K. Chromosome count on banana root tip squashes. Fruits. 2008;63:179-81.

6. Blomme G, Eden-Green S, Mustaffa M, Nwauzoma B, Thangavelu R. Major diseases of banana. In: Pillay M, Tenkuano A, editors. Banana breeding: progress and challenges. Boca Raton: CRC Press; 2011. p. 85-120.

7. Bretagnolle F, Thompson JD. Gametes with the somatic chromosome number: mechanisms of their formation and role in autopolyploid plants' evolution. New Phytol. 1995;129(1):1-22.

8. D'Hont A, Denoeud F, Aury J, Baurens F, Carreel F, Garsmeur $\mathrm{O}$, et al. The banana (Musa acuminata) genome and the evolution of monocotyledonous plants. Nature. 2012;488:213-9.

9. Dale J, James A, Paul J-Y, Khanna H, Smith M, Peraza-Echeverria $\mathrm{S}$, et al. Transgenic Cavendish bananas with resistance to Fusarium wilt tropical race 4. Nat Commun. 2017. https://doi.org/10. 1038/s41467-017-01670-6. 
10. De Capdeville G, Souza Júnior MT, Szinay D, Diniz LEC, Wijnker E, Swennen R, et al. The potential of high-resolution BAC-FISH in banana breeding. Euphytica. 2009;166(3):431-43.

11. de Jong H, van Eden J, Sybenga J. Synaptonemal complex formation and metaphase I configuration patterns in a translocation heterozygote of rye (Secale cereale). Genome. 1989;32:72-81.

12. de Jong H, Fransz P, Zabel P. High resolution FISH in plants techniques and applications. Trends Plant Sci. 1999;4:258-63.

13. Dobzhansky T, Sturtevant AH. Inversions in the chromosomes of Drosophila pseudoobscura. Genetics. 1938;23:28-64.

14. Dodds K. Genetical and cytological studies of Musa. Certain edible diploids J Genet. 1943;45:113-38.

15. FAO. Banana Market Review 2019. Rome: FAO; 2020.

16. Fortescue JA, Turner DW. Pollen fertility in Musa: viability in cultivars grown in southern australia. Aust J Agric Res. 2004;55(10):1085-91.

17. Häkkinen M. Reappraisal of sectional taxonomy in Musa (Musaceae). Taxon. 2013;62(4):809-13.

18. Heslop-Harrison JS, Schwarzacher T. Domestication, genomics and the future for banana. Ann Bot. 2007;100:1073-84. 4. FAO. Banana Market Review 2019. Rome: FAO; 2020.

19. Iovene M, Wielgus SM, Simon PW, Buell CR, Jiang J. Chromatin structure and physical mapping of chromosome 6 of potato and comparative analyses with tomato. Genetics. 2008;180:1307-17.

20. Kantama L, Wijnker E, Jong H De. Optimisation of cell spreading and image quality for the study of chromosomes in plant tissues. In: Schmidt A, editor. Plant Germline Development: Methods and Protocols. Springer Science; 2017. pp. 141-58.

21. Kayat F, Bonar N, Waugh R, Rajinder S, Rahimah AR, Rashid $\mathrm{AR}$, et al. Development of a genetic linkage map for genes associated with resistance and susceptibility to Fusarium oxysporum $\mathrm{f}$. sp. cubense from an F1 hybrid population of Musa acuminata ssp. malaccensis. Acta Hortic. 2009; 828:333-40.

22. Khayat E. Targeted improvement of Cavendish clones. In: Kema G, Drenth A, editors. Achieving sustainable cultivation banana Vol 2: Germplasm and genetic improvement. Cambridge, UK: Burleigh Dodds Science Publishing; 2020.

23. Levitt D, King M. Methanol fixation permits flow cytometric analysis of immunofluorescent stained intracellular antigens. J Immunol Methods. 1987;96:233-7.

24. Maguire MP, Riess RW. The relationship of homologous synapsis and crossing over in a maise inversion. Genet Soc Am. 1994;137:281-8.

25. Martin G, Baurens F, Droc G, Rouard M, Cenci A, Kilian A, et al. Improvement of banana Musa acuminata reference sequence using NGS data and semi-automated bioinformatics methods. BMC Genomics. 2016;17(243).

26. Martin G, Baurens F, Hervouet C, Salmon F, Delos J, Labadie K, et al. Chromosome reciprocal translocations have accompanied subspecies evolution in bananas. Plant J. 2020;104:1698.

27. Maryani N, Lombard L, Poerba YS, Subandiyah S, Crous PW, Kema GHJ. Phylogeny and genetic diversity of the banana Fusarium wilt pathogen Fusarium oxysporum f. sp. cubense in the Indonesian centre of origin. Stud Mycol. 2019;92:155-94.

28. Moens P. A new interpretation of meiotic prophase in Lycopersicon esculentum (tomato). Chromosoma. 1964;15:231-42.

29. Morán AJF. Improvement of cavendish banana cultivars through conventional breeding. Van den Bergh I, editor. Acta Hortic. 2013;986:205-8.
30. Ordonez N, Seidl MF, Waalwijk C, Drenth A, Kilian A, Thomma BPHJ, Ploetz RC, Kema GHJ. Worse comes to worst: bananas and panama disease-when plant and pathogen clones meet bananas: their origin and global rollout. PLoS Pathog. 2015;11(11):e1005197.

31. Ortiz R, Vuylsteke D. Inheritance of dwarfism in plantain (Musa spp., AAB group). Plant Breed. 1995;114(5):466-8.

32. Osuji J, Okoli BE, Edeoga HO. Karyotypes of the A and B Genomes of Musa L. Cytologia. 2006;71(1):21-4.

33. Park HR, Park JE, Kim JH, Shin H, Yu SH, Son S, et al. Meiotic chromosome stability and suppression of crossover between nonhomologous chromosomes in xBrassicoraphanus, an intergeneric allotetraploid derived from a cross between Brassica rapa and Raphanus sativus. 2020;11:1-12.

34. Peraza-Echeverria S, Dale JL, Harding RM, Smith MK,, Collet C. Characterization of disease resistance gene candidates of the nucleotide binding site (NBS) type from banana and correlation of a transcriptional polymorphism with resistance to Fusarium oxysporum f.sp.

35. Ploetz RC. Panama disease: an old nemesis rears its ugly head, Part 1. The begining of the banana export trades. Plant Heal Prog. 2005; https://doi.org/10.1094/PHP-2005-1221-01-RV.

36. Raboin LM, Carreel F, Noyer JL, Baurens FC, Horry JP, Bakry $\mathrm{F}$, et al. Diploid ancestors of triploid export banana cultivars: molecular identification of $2 \mathrm{n}$ restitution gamete donors and $\mathrm{n}$ gamete donors. Mol Breed. 2005;16(4):333-41.

37. Ramanna MS, Jacobsen E. Relevance of sexual polyploidisation for crop improvement-a review. Euphytica. 2003;133:3-18.

38. Rekha A, Hiremath SC. Chromosome studies and karyotype analysis of some triploid banana (Musa species) cultivars of AAA genomic group. J Hort Sci. 2008;3(1):30-4.

39. Roux NS, Toloza A, Dolezel J, Panis B. Usefulness of embryogenic cell suspension cultures for the induction and selection of mutants in Musa spp. In: Jain S, Swennen R, editors. Banana improvement: cellular, molecular biology and induced mutations. New Hempshire, USA: Science Publisher; 2004. p. 33-43.

40. Sass J. Botanical microtechnique. Ames, Iowa: Iowa State Univ. Press; 1964.

41. Shepherd K. Cytogenetics of the genus Musa. Montpellier, France: International Network for the Improvement of Banana and Plantain; 1999.

42. Simmonds NW, Shepherd K. The taxonomy and origins of the cultivated bananas. J Linn Soc London, Bot. Blackwell Publishing Ltd; 1955;55(359):302-12.

43. Šimoníková D, Nemecková A, Cížková J, Brown A, Swennen R, Doležel J. Chromosome painting in cultivated bananas and their wild relatives (Musa spp.) reveals differences in chromosome structure. Int J Mol Sci. 2020;21:7915.

44. Wilson GB. Cytological studies in the Musae. I. Meiosis in some triploid clones. Genetics. 1946;31:241-58.

45. Wilson GB. Cytological studies in the Musae. II. Meiosis in some diploid clones. Genetics. 1946;31:475-82.

46. Wilson GB. Cytological studies in the Musae. III. Meiosis i n some seedling clones. Genetics. 1946;31:483-93.

Publisher's Note Springer Nature remains neutral with regard to jurisdictional claims in published maps and institutional affiliations. 